Revista Brasileira de Farmacognosia Brazilian Journal of Pharmacognosy 21(4): 652-661, Jul./Aug. 2011

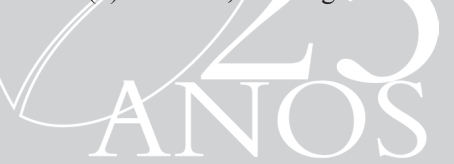

Article

Received 29 Nov 2010

Accepted 8 Jan 2011

Available online 17 Jun 2011

Keywords:

alkylamides

avicennol

canthinone alkaloids

Heme-drug adducts

Plasmodium falciparum

Zanthoxylum chiloperone

ISSN 0102-695X

doi: 10.1590/S0102-695X2011005000104

\section{The antiplasmodium effects of a traditional South American remedy: Zanthoxylum chiloperone var. angustifolium against chloroquine resistant and chloroquine sensitive strains of Plasmodium falciparum}

\author{
Gerardo Cebrián-Torrejón, ${ }^{1 \S}$ Kevin Spelman, ${ }^{2 \S}$ Karine Leblanc, ${ }^{1}$ \\ Katalina Muñoz-Durango, ${ }^{1}$ Sandra Torijano Gutiérrez, ${ }^{1}$ Maria \\ Elena Ferreira, ${ }^{3}$ Antonieta Rojas de Arias, ${ }^{4}$ Bruno Figadère, ${ }^{1}$ \\ Alain Fournet, ${ }^{, 5}$ Alexandre Maciuk, ${ }^{1}$ Philippe Grellier, ${ }^{6}$ Nadja \\ B. Cech, ${ }^{7}$ Erwan Poupon ${ }^{1}$
}

${ }^{1}$ Laboratoire de Pharmacognosie associé au CNRS, UMR 8076 BioCIS, Faculté de Pharmacie, Université Paris-Sud, France,

${ }^{2}$ Bioanalytical Chemistry and Drug Discovery Section, Laboratory of Clinical Investigation, National Institute on Aging, National Institute Health, USA,

${ }^{3}$ Department of Tropical Medicine, Instituto de Investigaciones en Ciencias de la Salud Asunción, Universidad Nacional de Asunción, Paraguay,

${ }^{4}$ Centro para el Desarrollo de la Investigación Cientifica (CEDIC/FMB/Diaz Gill Medicina Laboratorial), Asunción, Paraguay,

${ }^{5}$ IRD UMR217, Laboratoire de Pharmacognosie, Faculté de Pharmacie, France,

${ }^{6}$ Muséum National d'Histoire Naturelle, FRE 3206 CNRS, Département Régulations, Développement et Diversité Moléculaire, France,

${ }^{7}$ Department of Chemistry and Biochemistry, University of North Carolina Greensboro, USA.

\begin{abstract}
Zanthoxylum chiloperone var. angustifolium Engl., Rutaceae, is used in traditional medicine to treat fungal and protozoal infections in the central area of South America. Considering the increasing resistance of Plasmodium falciparum in malarial ridden areas, we explored the anti-plasmodial effects of three compounds isolated from $Z$. chiloperone. The pyranocoumarin transavicennol and the canthinone alkaloids, canthin-6-one and 5-methoxycanthin-6one, were found to have IC50 on chloroquine/mefloquine resistant and sensitive strains of $P$. falciparum of $0.5-2.7,2.0-5.3$ and $5.1-10.4 \mu \mathrm{g} / \mathrm{mL}$, respectively. Moreover, the formation of heme adducts by these compounds is described by a novel alternative method based on MS-CID methods. The alkylamide sanshool was also identified, for first time in this plant, in the dichloromethanic and ethanolic extracts and the extracts were found to be notably non-toxic and displayed good anti-plasmodial effects.
\end{abstract}

\section{Introduction}

In the majority of countries that cope with high malaria infection, medicinal plants contribute significantly to primary health care due to cultural traditions, and lack of access and affordability of pharmaceuticals. In addition, natural products are potential sources of new and selective agents for the treatment of important tropical diseases caused by protozoans (Karioti et al., 2009; Froelich et al., 2007; Luize et al., 2005). For example, Zanthoxylum chiloperone var. angustifolium Engl. (syn. Fagara chiloperone Engl. Ex Chod. \& Hassl.), Rutaceae, is a dioic tree indigenous to the central and southern continent of South America, which is called "tembetary hu" and "mamicão" (Spichiger \& Stutz de Ortega, 1987; Tabanez et al., 2005). A decoction of Z. chiloperone root and stem bark has been used in traditional medicine to treat malaria and for its emmenagogue and antirheumatic properties (Ferreira et al., 2007; Milliken, 1997). Recent studies have shown that the crude extract of the stem bark and leaves have 
activity against Trypanosoma cruzi (Ferreira et al., 2011; Ferreira et al., 2002) and antifungal activity in vitro (Thouvenel et al., 2003). Further investigations demonstrate that canthinone type alkaloids, canthin6-one and 5-methoxycanthin-6-one, are antifungal (Soriano-Agatón et al., 2005; Thouvenel et al., 2003) and effective in vivo against Leishmania amazonensis and Trypanosoma cruzi (Ferreira et al., 2011; Ferreira et al., 2007; Ferreira et al., 2002). Canthin-6-one has been suggested to be an inexpensive and safe treatment for use in long-term oral treatment as well as a good candidate against drug resistant strains of T. cruzi.

Other compounds were isolated from species of Zanthoxylum including the pyranocoumarin avicennol and alkylamides, such as the sanshools (Jang et al., 2008; Soriano-Agatón et al., 2005; Xiong et al., 1997; Yang, 2008). To date, there is a paucity of research on the biological activity of avicennol, which has been previously identified in Z. elephantiasis Macfad (Gray et al., 1977). Recent work with avicennol reports an induction of UDP-glucuronosyltransferases (UGT), specifically UGT1A1, which detoxifies xenobiotics (Chlouchi et al., 2007).

The alkylamides are a class of compounds which are well known in Asia, North America and Europe due to the tingling sensation on the tongue after ingestion of Sichuan pepper and Echinacea purpurea (Spelman et al., 2010). While many Zanthoxylum spp. are known to contain alkylamides, to the best of our knowledge there are no reports of the occurrence or identity of alkylamides in Z. chiloperone. Notably, these compounds have also been shown to be antiparastic (Lozano et al., 1984), as well as insecticidal (Jacobson, 1948). Recent reports have shown in vitro and in vivo anti-plasmodial activity of alkylamides identical to, or similar to, the alkylamides occurring in other Zanthoxylum spp. (Spelman et al., 2010).

One of the mechanisms of action of antimalarial drugs is based on their interference with the heme detoxication pathway (Weissbuch \& Leiserowitz, 2008). As a toxic, non-peptidic by-product of hemoglobin digestion, free heme must be sequestrated in the digestive vacuole. The biomineralization process involves the heme dimerization and the subsequent aggregation of dimers into hemozoin, an insoluble pigment. Antimalarial drugs are known to form adducts with heme, thus impairing heme polymerization and leading to the death of parasites at the trophozoite stage. Artemisinin for instance has been showed to form a covalent complex between heme and the alkylating species generated by the endoperoxide ring opening through Fe(II)-mediated catalysis (Robert et al., 2002). The free heme in its commercial form (hemin or hematin) is known to be suited for testing heme polymerization inhibition (Tekwani \& Walker, 2005).
Most of the protocols are based on spectrophotometry or radioactivity monitoring. (Garavito et al., 2007; Kurosawa et al., 2000; Rush et al., 2009). A novel method based on mass spectrometry can be used as an alternative method to detect heme-drug adducts (Figadère et al. 2010). It has been used to detect adducts between $\mathrm{Fe}$ (III)-heme and quinine, artemisinin and its derivatives. (Bilia et al., 2002; Pashynska et al., 2004). Our laboratory used mass spectrometry and insource collision-induced dissociation (CID) to assess the stability of the adducts. In our method, heme is incubated with the compound and analyzed by mass spectrometry using an increasing fragmentor voltage to dissociate the formed adduct. A relative assessment of the adduct stability can be obtained and compared to one reference compound, like quinine.

Thus far there has been limited exploration of Zanthoxylum chiloperone's chemistry and biological activity. The experiments continued herein describe the isolation of two alkaloids and a pyranocoumarin, the identification of an alkylamide and the anti-malarial activity of the crude extracts and the isolated compounds. In addition, using mass spectrometry and in-source CID to study the formation and stability of the heme adducts with avicennol and the canthinone alkaloids, we propose a possible basis for the antiplasmodial activity of these Zanthoxylum compounds.

\section{Material and Methods}

\section{General experimental procedures}

Yields refer to chromatographically and spectroscopically homogeneous materials, unless otherwise stated. Extraction was monitored by TLC carried out on Merck Kieselgel silica gel plates (60F254) using UV light as visualizing agent and sulfuric vanillin or Dragendorff reagent and heat as developing agent. Merck Kieselgel silica gel (60, particle size 40-63 $\mu \mathrm{m}$ ) was used for flash chromatography. NMR spectra were recorded on an AM-400 Bruker spectrometer and calibrated using undeuterated solvent as an internal reference. IR spectra were recorded on Vector 22 Bruker spectrometer and values are reported in $\mathrm{cm}^{-1}$ units. Mass spectra were recorded at "Service d'Analyse des Médicaments et Métabolites", SAMM, Université Paris-Sud, Châtenay-Malabry, France and University of North Carolina, Greensboro, North Carolina, U.S.A.

\section{Plant material}

Stem bark of Zanthoxylum chiloperone var. angustifolium Engl., Rutaceae, was collected by Maria Elena Ferreira, in Paraguay near Piribebuy, Department 
of Cordillera and identified by N. Soria (Department of Botany, National University of Asuncion, Paraguay). A voucher specimen (AF 917) has been deposited at the Herbarium of Chemical Sciences Faculty, San Lorenzo, Paraguay.

\section{Extraction and isolation}

Powdered dried stem bark of $Z$. chiloperone var. angustifolium (1.3 kg) was basified with ammonia, extracted in a Soxhlet apparatus with $\mathrm{CH}_{2} \mathrm{Cl}_{2}$ and $\mathrm{MeOH}$ separately and successively for three days to afford 23 and $30 \mathrm{~g}$ of crude extracts, respectively. The yields of the dichloromethane and the methanol extracts were approximately 1.7 and $2.3 \%$, respectively, of the plant powder. Both extracts were evaluated for antiplasmodial activity and the $\mathrm{CH}_{2} \mathrm{Cl}_{2}$ extract showed greater antimalarial activity. Therefore, the $\mathrm{CH}_{2} \mathrm{Cl}_{2}$ extract was subjected to silica gel flash column chromatography, eluted with $\mathrm{CH}_{2} \mathrm{Cl}_{2}$ /ethyl acetate (8:2), to obtain 42 fractions. Fractions $10-18$ were combined providing $3.5 \mathrm{~g}$ of trans-avicennol (1) a yellow crystal (yield of 15.2 and $0.3 \%$ respectively from the dichloromethane extract and plant powder). Fractions 21-30 were combined obtaining $3 \mathrm{~g}$ of canthin-6-one (2), a yellow crystalline powder (yield of 13 and $0.2 \%$, respectively). Fractions 33-39 were combined yielded $1.5 \mathrm{~g}$ of 5 -methoxycanthin-6-one (3), a brown crystalline powder (with a yield of 6.5 and $0.11 \%$, respectively). Physical and spectral data were used to determine the chemical structure of the compounds and compared to reference samples and literature values $\left({ }^{1} \mathrm{H},{ }^{13} \mathrm{C}\right.$ NMR, MS, HRMS, IR).

The powered stem-bark (5 g) was basified with ammonia, extracted by ethanol maceration over two days, changing the solvent three times, for a yield of $2.3 \%$. The compositions of the ethanol and the dichloromethane extracts were studied by HPLC-UVMS method.

\section{Analysis by HPLC-UV-MS and MS/MS methods}

\section{HPLC-UV-MS qualitative study}

A LC/MSD 1100 series +1100 series (Agilent Technologies) spectrometer was utilized in the HPLC study of the extracts by using a $150 \mathrm{~mm}$ x $4.6 \mathrm{~mm}$ stainless-steel column Sunfire (Waters) C18. The eluents were (A) $\mathrm{H}_{2} \mathrm{O}+\mathrm{TFA} 0.1 \%$ and (B) $\mathrm{MeOH}+0.1 \%$ TFA. Separations were performed at room temperature by solvent gradient elution from $50 \% \mathrm{~A} / 50 \%$ B to $20 \%$ $\mathrm{A} / 80 \% \mathrm{~B}$ in $20 \mathrm{~min}$ then to $100 \% \mathrm{~B}$ in $12 \mathrm{~min}$ at a flow rate of $1 \mathrm{~mL} / \mathrm{min}$.

The UV measurement was made at 240 and 260 $\mathrm{nm}$. The injection volume was $5 \mu \mathrm{L}$. Peak identification was performed by comparison of the retention time $\left(\mathrm{t}_{\mathrm{r}}\right)$, UV absorption and mass study at the different wavelengths with the compounds trans-avicennol (1), canthin-6-one (2), 5-methoxy-canthin-6-one (3) as references (Figure 1).

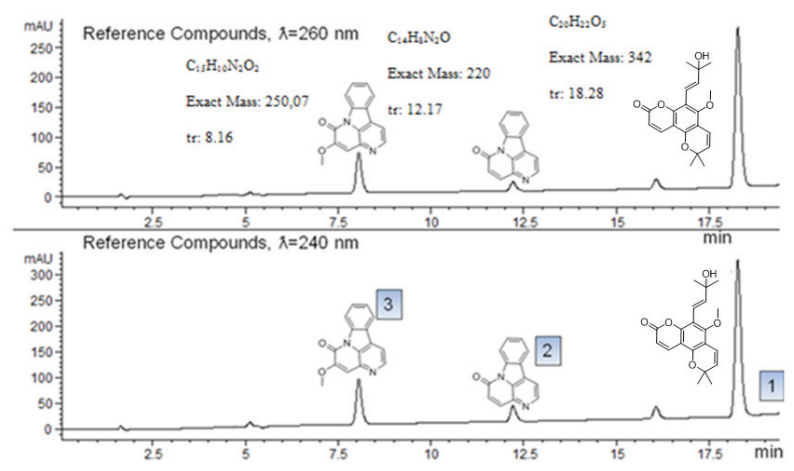

Figure 1. HPLC-UV Chromatogram of reference compounds $(\lambda=260$ and $240 \mathrm{~nm})$.

Figure 2 illustrates the HPLC-UV chromatogram of the dichloromethane and alcohol extracts of stem bark extract of the plant $Z$. chiloperone.

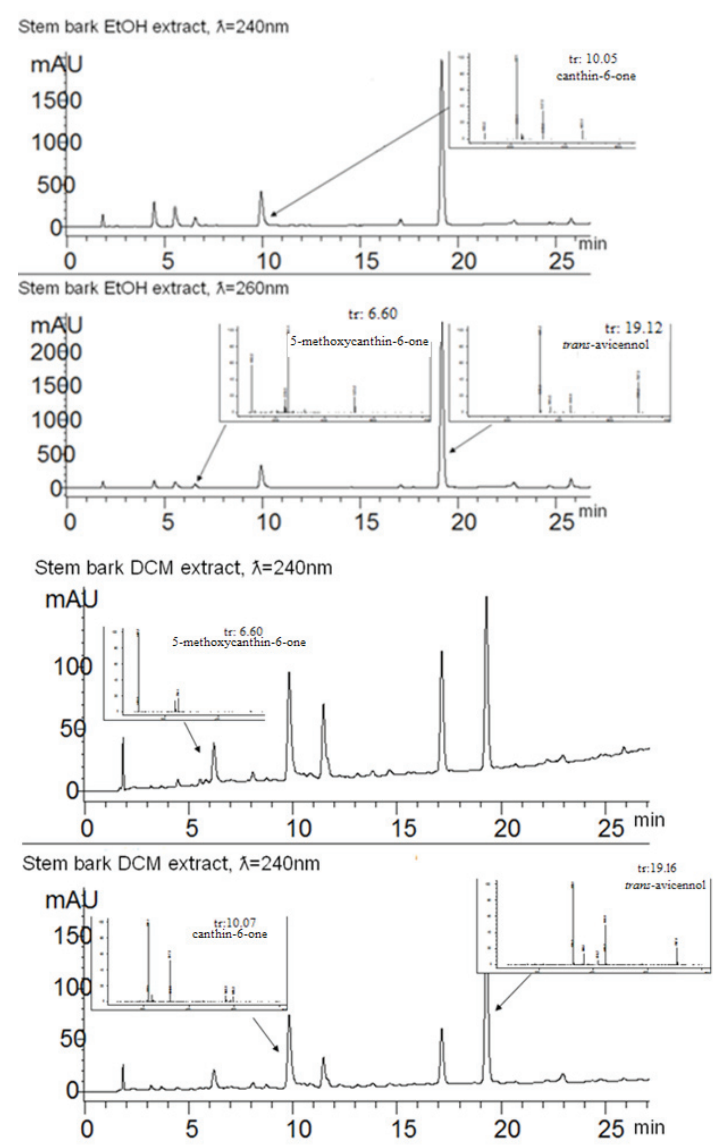

Figure 2. HPLC-UV Chromatogram of extracts of $Z$. chiloperone. The chromatographic profile (HPLC-UV-MS) of ethanol and dichloromethane extracts of $Z$. chiloperone obtained through maceration and soxhlet extraction illustrate the peaks for the canthinones and avicennol before $20 \mathrm{~min}$. 


\section{HPLC-UV quantitative study}

The quantification analysis was performed by external standard method, using a calibration curve constructed utilizing solutions containing different concentrations of the three reference samples (1-3). The stock solutions were prepared in a mixture $\mathrm{MeOH}+\mathrm{DMSO}$ and then diluted with the mobile phase in various proportions. The calibration curves of the different samples represent the concentration " $C$ " of each reference molecule versus the area under the peak " $\mathrm{S}$ "; this graphic presents a linearity behaviour $(\mathrm{C}=\mathrm{a}+\mathrm{bS})$ in the interval of concentrations from 0.01 to $0.3 \mathrm{mg} / \mathrm{mL}$.

All the samples for HPLC analysis were operated directly without any previous purification. A modular system comprised of 600 E controller + pump and a 2996 PDA UV (Waters) detector was utilized in the HPLC-UV quantification experiment.

Reference compounds stock solutions of 10 , 50, 100, 150, 200, $300 \mu \mathrm{g} / \mathrm{mL}$ were utilized. Each determination was carried out in triplicate. The calibration curve showed the linearity of the detector over the tested range $(10-300 \mu \mathrm{g} / \mathrm{mL})$. The $\mathrm{R}^{2}$ of the calibration curve is linear and 0,999. The quantitative evaluation of the peaks previously identified in the crude extracts was made by integration of the peak area and comparison with the area of the corresponding reference peak (Table 1).

Table 1. Concentrations of compounds in the ethanol and dichloromethane extracts.

\begin{tabular}{llll}
\hline (mg/g extract) & 1 & 2 & 3 \\
\hline Stem bark DCM & 63.2 & 64.7 & 29.4 \\
Stem bark EtOH & 85.6 & 85.6 & 19.1 \\
\hline
\end{tabular}

\section{MS/MS study}

To elucidate the presence of alkylamides, LCESI-MS/MS analysis was conducted on the crude extracts of $Z$. chiloperone ramulus cortex using the previously established structures of alkylamides identified in related Zanthoxylum spp. and the results of a previously validated LC-ESI-MS/MS method for the identification of alkylamides (Spelman et al., 2009). An ion trap mass spectrometer with electrospray ionization source (LCQ Advantage, ThermoFisher, San Jose, CA) was employed.
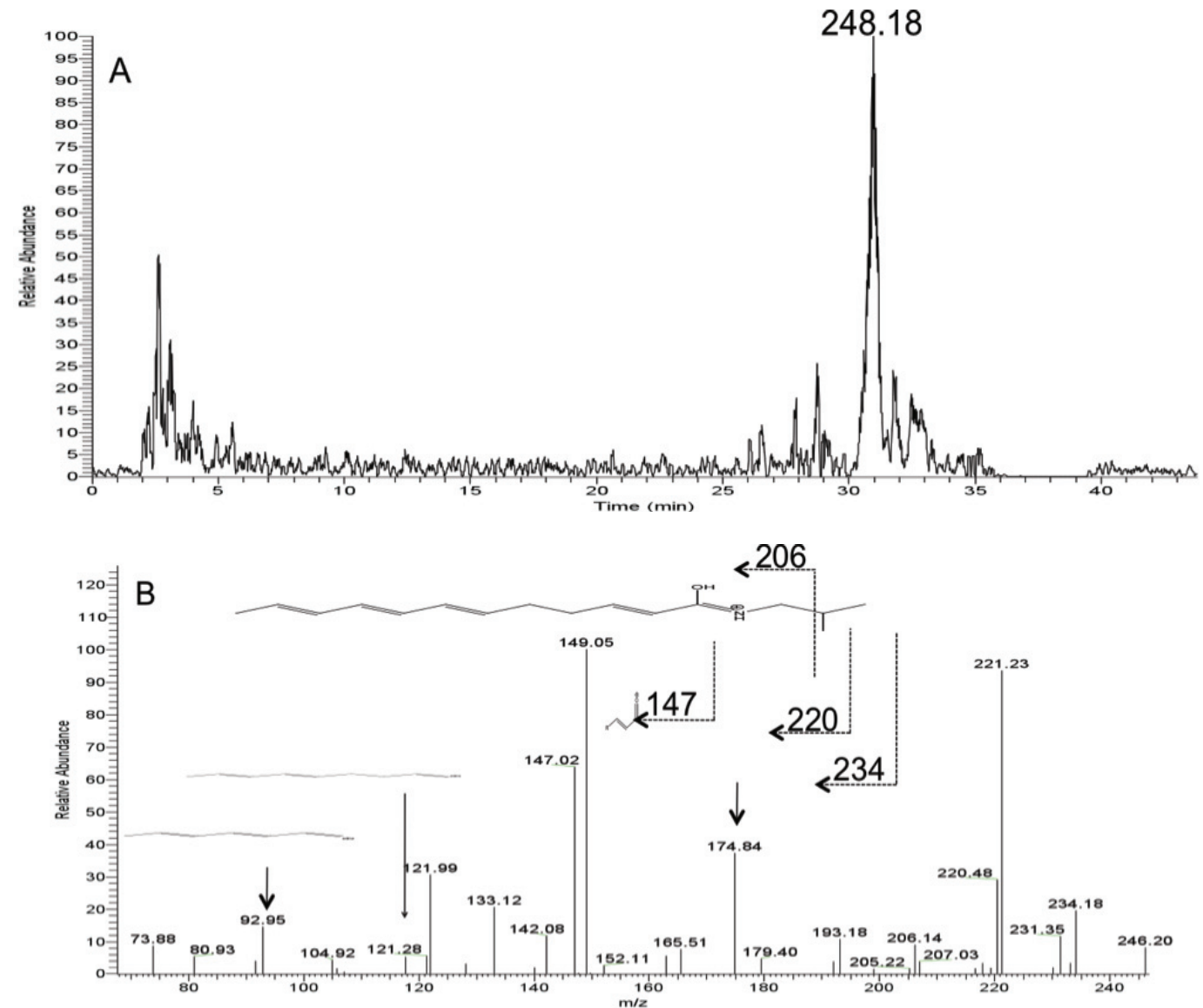

Figure 3. Selected ion chromatogram and MS/MS Spectra of dodeca-2,6,8,10-tetraenoic acid isobutylamide (4). A. The selected ion chromatogram illustrates the $\mathrm{M}^{+}$ion at $\mathrm{m} / \mathrm{z} 248$. B. The MS/MS spectra of the $248 \mathrm{M}^{+}$ion identifies the compound as the alkylamide sanshool (4), dodeca-2,6,8,10-tetraenoic acid isobutylamide although the stereochemistry cannot be identified. The structure shown is that of the protonated $\left(\mathrm{M}^{+}\right)$form of sanshool 4 . 
The solvent gradient, which was a minor variation on that previously published (Spelman et al., 2009), was as follows, where solvent $A$ is aqueous acetic acid $(17 \mathrm{mM}$, original $\mathrm{pH}$ 2.74) and solvent $B$ is neat HPLC grade acetonitrile. For $\mathrm{t}=0$ to $4 \mathrm{~min}$, a constant composition of $\mathrm{A}-\mathrm{B}(90: 10 \mathrm{v} / \mathrm{v})$; for $\mathrm{t}=4$ to $15 \mathrm{~min}$, a linear gradient from $\mathrm{A}-\mathrm{B}(90: 10, \mathrm{v} / \mathrm{v})$ to $\mathrm{A}-\mathrm{B}(60: 40, \mathrm{v} / \mathrm{v})$; for $\mathrm{t}=15$ to $30 \mathrm{~min}$, a linear gradient from A-B $(60: 40, v / v)$ to A-B $(40: 60, v / v)$; for $\mathrm{t}=30.1$ to 35 min, a constant composition of $\mathrm{A}-\mathrm{B}(0: 100, \mathrm{v} / \mathrm{v})$; for $\mathrm{t}=35.1$ to $43 \mathrm{~min}$, a constant composition of A-B $(90: 10, \mathrm{v} / \mathrm{v})$. The mass spectrometer was operated in the positive ion mode with a scan range of 50.00-2000.00. Spray, capillary, and tube lens offset voltages were $4.5 \mathrm{kV}, 3 \mathrm{~V}$ and $-60 \mathrm{~V}$, respectively (Figure 3).

MS-CID study of the heme-compounds $(\mathbf{1}, \mathbf{2}, \mathbf{3})$ adducts

Methanol HPLC grade was obtained from VWR (Fontenay-sous-Bois, France) and deionized water from a SynergyUV deionizer from Millipore (Molsheim, France). DMSO was obtained from Sigma-Aldrich (Lyon, France). Hemin was obtained from Alfa Aesar (Schiltigheim, France). Bulk solutions $(5 \mathrm{mM})$ were made for avicennol 1, canthin-6-one 2, 5-methoxycanthin-6-one 3, quinine in methanol and for heme in $\mathrm{NH}_{4} \mathrm{OH}: \mathrm{H}_{2} \mathrm{O}$ (1:7). Using methanol as dilution solvent, a mixture of each compound $(250 \mu \mathrm{M})$ and heme $(250 \mu \mathrm{M})$ in a final volume of 100 $\mu \mathrm{L}$ was incubated $30 \mathrm{~min}$ in a water bath at $37^{\circ} \mathrm{C}$. The incubates $(2 \mu \mathrm{L})$ were injected using $\mathrm{MeOH}: \mathrm{H}_{2} \mathrm{O}(3: 1)$ as mobile phase at $200 \mu \mathrm{L} / \mathrm{min}$ in an Agilent LC/MSD 1100 Series HPLC-mass spectrometer system (Santa Clara, USA) using electrospray positive mode ionization, drying gas at $350{ }^{\circ} \mathrm{C}, 10 \mathrm{~L} / \mathrm{min}$ and 35 psig and capillary voltage of $3000 \mathrm{~V}$. The mass spectra were recorded in the mass range $m / z$ 100-2000. In-source CID was performed in single ion monitoring mode by applying an increasing fragmentor voltage from 160 to $400 \mathrm{~V}$ in a flow injection analysis sequence with $30 \mathrm{~V}$ increment steps (Figure 4). Data are plotted so as to show the ion abundance of the adduct at the maximum of the injection peak versus the fragmentor voltage, and fitted by a sigmoidal curve using the GraphPad Prism software (Figure 6).

\section{Biological assays}

Anti-Plasmodium falciparum resistant and sensitive strains activity

After isolation of trans-avicennol 1, canthin6-one 2 and methoxycanthin-6-one $\mathbf{3}$, the half maximal inhibitory concentrations (IC50) of extracts and the previously listed compounds were assessed by determining the concentration inhibiting $50 \%$ of parasite growth (Table 2, Figure 5). The IC50 determined against the Colombian chloroquine-resistant FcB1 strain, the Brazilian mildly chloroquine-resistant strain $\mathrm{PFB}$, the multi-drug and chloroquine-resistant strain K1 from Thailand, and the chloroquine-sensitive, but mefloquine resistant Tanzanian strain F32 were determined using a previously established method (Desjardins et al., 1979).
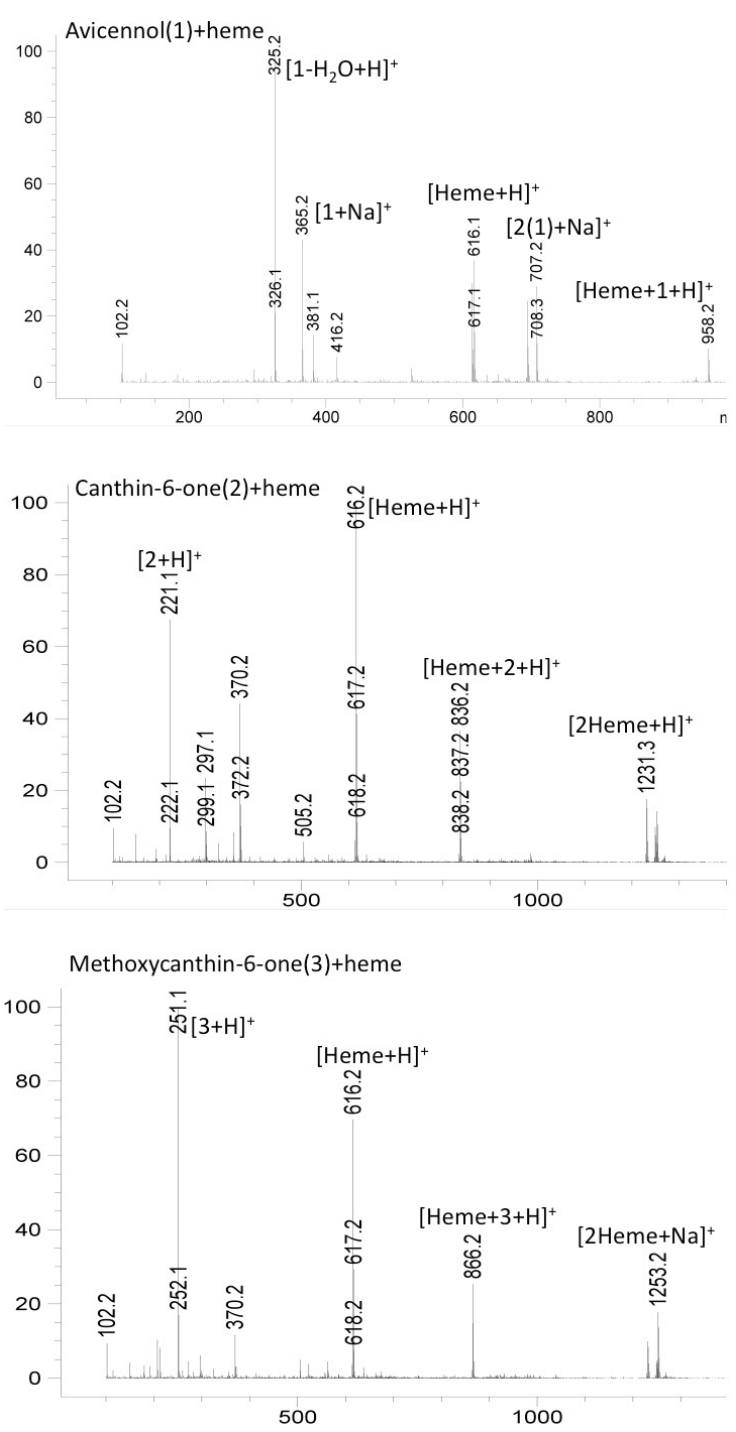

Figure 4. Mass spectra of incubates of heme and transavicennol (1), canthin-6-one (2) and 5-methoxycanthin-6one (3).

\section{Hemolytic activity}

In order to confirm that the antimalarial activities measured by $\left[{ }^{3} \mathrm{H}\right]$ hypoxanthine incorporation are due to the intrinsic antiparasite property of the experimental compounds and not due to hemolytic activity, a standard hemolysis assay was run. After $48 \mathrm{~h}$ incubation time in the presence of the various test compounds, the hemolysis of non-infected erythrocytes was measured at $530 \mathrm{~nm}$ 
incubated for $48 \mathrm{~h}$ at concentrations up to $100 \mu \mathrm{g} / \mathrm{mL}$.

Table 2. IC50 of Z. chiloperone isolated compounds and extracts.

\begin{tabular}{lcccc}
\hline \multirow{2}{*}{ Compounds } & \multicolumn{4}{c}{ P. falciparum strain $\mathrm{IC50}(\mu \mathrm{g} / \mathrm{mL})$} \\
\cline { 2 - 5 } & $\mathrm{F} 32$ & $\mathrm{~K} 1$ & $\mathrm{PFB}$ & $\mathrm{FcB} 1$ \\
\hline Trans-avicennol (1) & 0.5 & 2.7 & 1.2 & 2.2 \\
Canthin-6-one (2) & 2.0 & 5.3 & 3.2 & 4.0 \\
$\begin{array}{l}\text { 5-methoxycanthin-6- } \\
\text { one (3) }\end{array}$ & 10.4 & 5.1 & $\mathrm{Nt}$ & $\mathrm{Nt}$
\end{tabular}

\begin{tabular}{lcccc}
\hline Extracts & & & & \\
\hline $\mathrm{DCM}$ & 8.9 & 8.9 & $N t$ & $N t$ \\
$\mathrm{EtOH}$ & 10.5 & 9.3 & $N t$ & $N t$ \\
$\mathrm{MeOH}$ & 89.5 & $>100$ & $N t$ & $N t$
\end{tabular}

Positive Control

\begin{tabular}{|c|c|}
\hline Chloroquine & $* 2.6$ \\
\hline
\end{tabular}

*Chloroquine concentrations are in $\mathrm{nM}$; nt: not tested

Cytotoxic activity

The cytotoxicity of the plant extracts was determined using the colorimetric methylthiazoletetrazolium(MTT)assay(Mosmann, 1983). MRC5 cells were incubated for an extended period (five days) in the presence of trans-avicennol 1, canthin-6-one 2, 5-methoxycanthin-6-one $\mathbf{3}$, and the dichloromethane, ethanol and methanol extracts of $Z$. Chiloperone (Table 3 ), and scored as a percentage of absorbance reduction at $540 \mathrm{~nm}$ of treated cultures versus untreated control cultures. IC50 values on cell growth were obtained from the drug concentration-response curves and expressed as the means \pm the standard deviations determined from triplicate independent experiments.

Table 3. Cell survival of MCR5 cells incubated with $Z$. chiloperone isolated compounds and extracts.

\begin{tabular}{lc}
\hline Experimental compound(s) & IC50 $(\mu \mathrm{g} / \mathrm{mL})$ \\
\hline Trans-avicennol (1) & 4.4 \\
Canthin-6-one (2) & 9.4 \\
MeOH extract & $>100$ \\
DCM extract & 12.3 \\
EtOH extract & 13.0
\end{tabular}

DCM: dichloromethane; EtOH: ethanol, $\mathrm{MeOH}$ : methanol.

\section{Results and Discussion}

Qualitative and quantitative analysis of Z . chiloperone stem bark dichloromethane and ethanol extracts

Analysis using HPLC-UV-MS methods

The composition of each organ of $Z$. chiloperone was analyzed by HPLC-UV-MS study of the ethanol and dichloromethane extracts of stem bark. The qualitative studies identified the main compounds in Z. chiloperone, such as the coumarin trans-avicennol 1 and canthin-6one alkaloids, i.e. canthin-6-one 2, 5-methoxy-canthin-6one 3. The compounds were identified by their retention times (tr) and by their mass spectra respectively (see also Figures 1 and 2: chromatographic profiles of the reference compounds and profiles of the respective ethanol and dichloromethane extracts).
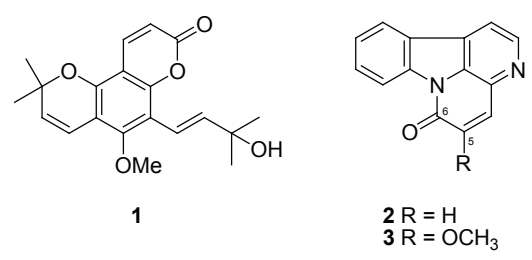

The quantitative analysis was performed by the external standard method, using a calibration curve constructed utilizing solutions containing different concentrations of the three reference samples, transavicennol 1, canthin-6-one 2 and 5-methoxy-canthin6-one 3. The concentrations of trans-avicennol $\mathbf{1}$ in the dichloromethane and ethanol extract of the stem bark are 63.2 and $85.6 . \mathrm{mg} / \mathrm{g}$ extract respectively, while the concentrations of canthin-6-one $\mathbf{2}$ in the same extracts are 64.7 and $85.6 \mathrm{mg} / \mathrm{g}$ extract respectively, finally the concentrations of 5-methoxycanthin-6-one $\mathbf{3}$ are 29.4 and $19.1 \mathrm{mg} / \mathrm{g}$ of extract respectively (Table 1 ).

MS/MS of Z. chiloperone demonstrates the presence of alkylamides

Previous reports have shown a substantial profile of alkylamides occurring in Zanthoxylum spp. (Jang et al., 2008; Xiong et al., 1997; Yang, 2008). However, to our knowledge, there have been no reports on the presence of alkylamides in Z. chiloperone. To elucidate the presence of alkylamides, LC-ESI-MS/MS analysis was conducted on the crude extracts of $Z$. chiloperone ramulus cortex using a previously validated method (Spelman et al., 2009). Figure $3 \mathrm{~A}$ illustrates a selected ion chromatogram obtained from analysis of the 1:2 dry stem bark of $Z$. chiloperone extract. The ion corresponds to the $m / z$ of the protonated $\left(\mathrm{M}^{+}\right)$ forms of one of the alkylamides in Z. chiloperone of MW 247. Figure 3B illustrates the MS/MS spectrum obtained by (CID) of the $\mathrm{M}+$ ion. For ease of reference, Figure $3 \mathrm{~B}$ and Table 4 illustrate the primary fragments obtained. These major groups of fragments are consistent with those previously observed for alkylamides (Spelman et al., 2009). They confirm the presence of compound $\mathbf{4}$, dodeca2,6,8,10-tetraenoic acid isobutylamide, also known as sanshool, in $Z$. chiloperone. Note that it is not possible to distinguish $\mathrm{E} / \mathrm{Z}$ isomers with the LC-MS method employed here. 
Table 4. Fragments formed by Collisionally Induced Dissociation (MS-MS) of the $\mathrm{M}^{+}$ion of various $Z$. chiloperone alkylamides.

\begin{tabular}{|c|c|c|c|c|c|c|c|}
\hline & Designation, name, $\mathrm{m} / \mathrm{z}$ & $\begin{array}{l}\text { group } i^{4} \\
\mathrm{RI}^{3} 37 \%\end{array}$ & $\begin{array}{c}\text { group } i i^{5} \\
\text { RI } 64 \%\end{array}$ & $\begin{array}{l}\text { group } i i i^{6} \\
\text { RI } 100 \%\end{array}$ & $\begin{array}{c}\text { group iv } \\
\text { RI } 9 \%\end{array}$ & $\begin{array}{c}\text { group } v^{8} \\
\text { RI } 19-29 \%\end{array}$ & $\begin{array}{l}\text { group } v i^{9} \\
\text { RI 5-14\% }\end{array}$ \\
\hline $248^{1}$ & $\begin{array}{l}\text { dodeca-2,6,8,10-tetraenoic acid } \\
\text { isobutylamide }\end{array}$ & 175 & 147 & 149 & 206 & 220,234 & $81,93,121,133$ \\
\hline
\end{tabular}

${ }^{1}$ The number beneath the letter designation indicates the $\mathrm{m} / \mathrm{z}$ value for the $\mathrm{M}^{+}$ion; ${ }^{2}$ Proposed structure for compound $\mathrm{E}$ based on retention time and MS/MS fragmentation; ${ }^{3} \mathrm{RI}$ corresponds to relative intensity; ${ }^{4}$ The group $\mathbf{i}$ fragments correspond to acyllium ions as shown in Figure 3 ; ${ }^{5}$ The group ii fragments are carbocations that correspond to the alkyl chain of the alkylamide and are formed by loss of the amide portion (isobutylamide or 2-methylbutylamide); ${ }^{6}$ The group iii fragments correspond to the alkyl chain of the alkylamide and are formed by the loss of the amide portion of the molecule and saturation of one of the double bonds on the akyl chain. The $m / z$ value of these fragments is +2 greater than the group ii fragments; ${ }^{7}$ The group iv fragments correspond to the protonated alkylamide minus the $\mathrm{N}$-alky group; ${ }^{8} \mathrm{The}$ group $\mathbf{v}$ fragments correspond to the protonated alkylamide minus various portions of the $\mathrm{N}$-alkyl group (see Fig. 3 for the bonds at which fragmentation occurs); ${ }^{9}$ The group vi fragments correspond to the varying carbocation fragments formed after loss of various portions of the $C$-alkyl group.

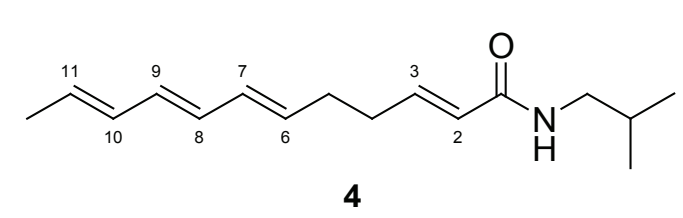

In vitro biological activity of isolated compounds and extracts of $\mathrm{Z}$. chiloperone towards $\mathrm{P}$. falciparum

After isolation of trans-avicennol 1, canthin6-one $\mathbf{2}$ and 5-methoxycanthin-6-one $\mathbf{3}$, the half maximal inhibitory concentrations (IC50) of extracts and the previously listed compounds were assessed by determining the concentration inhibiting $50 \%$ of parasite growth. The IC50 were determined against the Colombian chloroquine-resistant FcB1 strain, the Brazilian mildly chloroquine-resistant strain PFB, the multi-drug and chloroquine-resistant strain K1 from Thailand, and the chloroquine-sensitive, but mefloquine resistant Tanzanian strain F32. Figure 5 illustrates the IC50 for avicennol 1, canthine-6-one $\mathbf{2}$ and 5-methoxycanthin-6-one $\mathbf{3}$ on the Plasmodium falciparum strain F32. These data show that F32 is the most sensitive strain to avicennol 1 and canthin6-one 2 ( 0.5 and $2.0 \mu \mathrm{g} / \mathrm{mL}$, respectively). Further testing of additional $P$. falciparum strains demonstrated that these compounds all had approximately the same activity on $\mathrm{K} 1, \mathrm{PFB}$ and FcB1strains. Table 2 shows the results on parasite growth in tabulated form. Note that the crude extracts of $Z$. chiloperone demonstrated robust activity. This is possibly due to the combination of the canthin-6one type compounds, the pyranocoumarin, as well as the alkylamide(s), previously shown to be active against $P$. falciparum in vitro and $P$. yoelii yoelii in vivo (Spelman et al., 2010). Considering that traditional extracts of $Z$. chiloperone are used to treat Chagas disease, this is an intriguing finding and suggest that there may be various modes of Plasmodium inhibition due to the presence of multiple active compounds and possible unknown compounds as well.

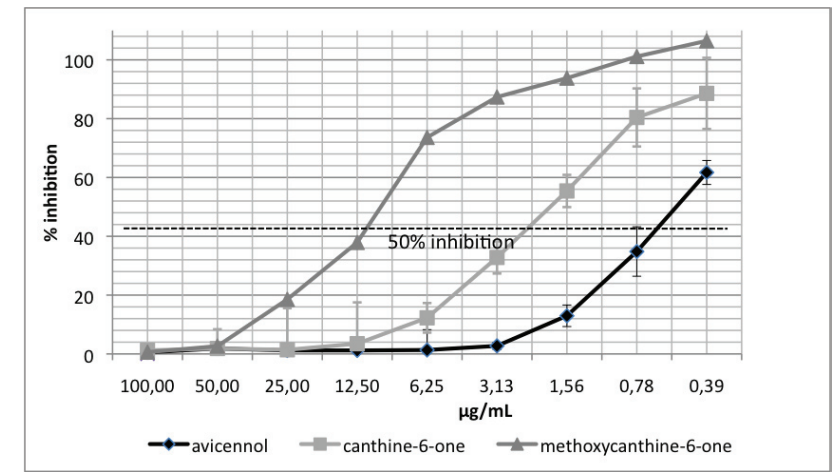

Figure 5. IC50 of isolated compounds from Z. chiloperone against $P$. facliparum F32. Avicennol shows an IC50 of $0.5 \mu \mathrm{g} /$ $\mathrm{mL}$; canthin-6-one and 5-methoxycanthin-6-one show IC50 of 2.0 and 10.4 , respectively.

IC50 values for the positive control chloroquine are also listed in Table 2. Note that the IC50 for our K1 clone of $P$. falciparum were considerably less than those published by Elueze et al. (1996) and Fivelman et al. (2007), but higher than Sharrock et al. (2008).

Study of hemolytic activity of compounds isolated from, and extracts of, $\mathrm{Z}$. chiloperone

In order to confirm that the antimalarial activities measured by $\left[{ }^{3} \mathrm{H}\right]$-hypoxanthine incorporation are due to the intrinsic antiparasite property of the experimental compounds and not due to hemolytic activity, a standard hemolysis assay was run. After $48 \mathrm{~h}$ incubation time in the presence of the various test compounds, the hemolysis of non-infected erythrocytes was measured at $530 \mathrm{~nm}$. Results demonstrated that trans-avicennol 1, canthin6-one $\mathbf{2}$ and 5-methoxycanthin-6-one $\mathbf{3}$, as well as the dichloromethane, ethanol and methanol extracts of $Z$. chiloperone incubated for $48 \mathrm{~h}$ at concentrations up to 100 $\mu \mathrm{g} / \mathrm{mL}$, had no haemolytic effect on erythrocytes. 
Cytotoxicity assay

To probe for cytotoxicity, MRC5 cells were incubated for an extended period (five days) in the presence of trans-avicennol 1, canthin-6-one $\mathbf{2}$ and 5-methoxycanthin-6-one $\mathbf{3}$, and the dichloromethane, ethanol and methanol extracts of $Z$. chiloperone. Table 3 shows the results of these assays. Trans-avicennol 1 had the most cytotoxic effect on MRC5 cells at an IC50 of $4.4 \mu \mathrm{g} / \mathrm{mL}$. The canthinone alkaloids, canthin-6-one 2 and 5-methoxycanthin-6-one 3, were observed to have IC50 at 12.1 and $12.3 \mu \mathrm{g} / \mathrm{mL}$, respectively. Supporting the frequent use of this plant species in traditional medicine, the crude extracts demonstrated less cytoxicity with the DCM extract and the ethanol extract showing 12.5 and $13.0 \mu \mathrm{g} / \mathrm{mL}$ IC50, respectively. The hydrophilic methanol extract had no detectable effect on cell survival up to 100 $\mu \mathrm{g} / \mathrm{mL}$.

MS-CID detection of the heme-compound (1, 2, 3) adducts

The formation of adducts between compounds and heme is an indication of the ability of the compound to interfere with hematin formation process and thus to show a potential antimalarial activity. Mass spectra from the incubates with heme (Figure 4) show a clear adduct for each of the compounds. The stability of the adducts between heme and the different isolated compounds were assessed by submitting the adducts to in-source CID and by comparing the results to the quinine adduct used as reference (Figure 6). Trans-avicennol 1 shows a relatively more stable adduct with heme than the canthin derivatives, which can be correlated with the differences of results in the in vitro assays. A slight difference of stability is observed between avicennol $\mathbf{1}$ and the canthin derivatives, suggesting a distinct level of binding to heme of the two skeletons. These data give an indication of the ability of these compounds to bind with heme as a major target for antimalarial compounds, although there is no yet established correlation between adduct stability under these conditions and biological activity.

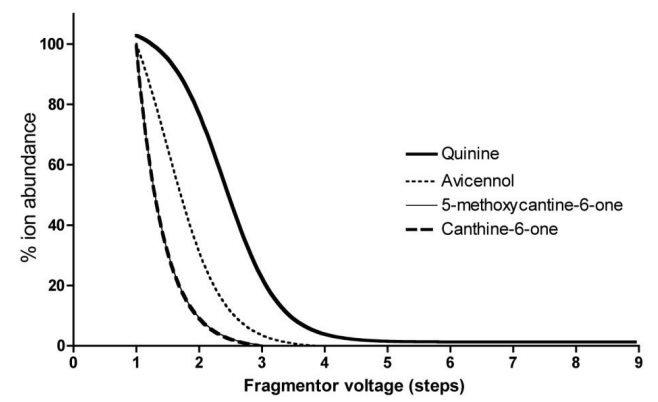

Figure 6. Stability of the heme-compound adducts vs fragmentor voltage.

\section{Conclusion}

The studies herein report the quantization, identification and isolation of compounds new to Zanthoxylum chiloperone including the pyranocoumarin avicennol 1 and the canthinone alkaloids canthin-6-one 2 and 5-methoxycanthin-6-one $\mathbf{3}$. In addition, we identified sanshool, dodeca-2,6,8,10-tetraenoic acid isobutylamide 4, in this species. We report a good antiplasmodial effect on chloroquine resistant and sensitive strains of $P$. falciparum for the pyranocoumarin avicennol 1 (LD50 of 0.5-2.7 $\mu \mathrm{g} / \mathrm{mL}$ ) and the canthinone alkaloids (LD50 of 2.0-5.3 $\mu \mathrm{g} / \mathrm{mL}$ and $5.1-10.4 \mu \mathrm{g} / \mathrm{mL}$ ) for canthin-6-one 2 and 5-methoxycanthin-6-one 3 , respectively. The generation of adducts, heme-avicennol and heme-canthinones, suggesst the basis that this activity may be at least partly explained through the heme detoxification pathway. Intriguingly, the dichloromethane and ethanol extracts showed robust effects on the chloroquine-resistant strain $\mathrm{K} 1$, and the chloroquine-sensitive, but mefloquine resistant Tanzanian strain F32 of $P$. falciparum. Considering these data, future improvements in antimalarial chemotherapy based on avicennol and the canthinone alkaloids could generate analogs with increased selectivity and lowered resistance index, and opens new horizons for targeting the increased mortality due to drug-resistant malaria.

\section{Acknowledgements}

The authors thank the European Community for the financial support (Marie Curie Early Stage Training Fellowship of the European Community's Sixth Framework Programme: contract BioMedChem (for G. CT., K. S. and K. MD.). Thanks are due to Mrs. A. Solgadi (SAMM) for MS experiments and Dra Nashira Campos Vieira (University of Brasilia) for the portuguese traduction.

\section{References}

Bilia AR, Lazari D, Messori L, Taglioli V, Temperini C, Vincieri FF 2002. Simple and rapid physico-chemical methods to examine action of antimalarial drugs with hemin: its application to Artemisia annua constituents. Life Sci 70: 769-778.

Chlouchi A, Girard C, Bonet A, Viollon-Abadie C, Heyd B, Mantion G, Martin H, Richert L 2007. Effect of chrysin and natural coumarins on UGT1A1 and 1A6 activities in rat and human hepatocytes in primary culture. Planta Med 73: 742-747.

Desjardins RE, Canfield CJ, Haynes JD, Chulay JD 1979. Quantitative assessment of antimalarial activity in vitro by a semiautomated microdilution technique. Antimicrob Agents Chemother 16: 710-718.

Elueze EI, Croft SL, Warhurst DC 1996. Activity of pyronaridine and mepacrine against twelve strains of Plasmodium falciparum in vitro. J Antimicrob Chemother 37: 511518. 
Ferreira ME, Cebrián-Torrejón G, Corrales AS, de Bilbao NV, Rolón M, Gomez CV, Leblanc K, Yaluf G, Schinini A, Torres S, Serna E, Rojas de Arias A, Poupon E, Fournet A 2011. Zanthoxylum chiloperone leaves extract: first sustainable Chagas disease treatment. J Ethnopharmacol 133: 986-993.

Ferreira ME, Nakayama H, de Arias AR, Schinini A, Serna E, Lagoutte D, Soriano-Agaton F, Poupon E, Hocquemiller R, Fournet A 2007. Effects of canthin-6-one alkaloids from Zanthoxylum chiloperone on Trypanosoma cruziinfected mice. J Ethnopharmacol 109: 258-263.

Ferreira ME, Rojas De Arias A, Torres De Ortiz S, Inchausti A, Nakayama H, Thouvenel C, Hocquemiller R, Fournet A 2002. Leishmanicidal activity of two canthin-6one alkaloids, two major constituents of Zanthoxylum chiloperone var. angustifolium. J Ethnopharmacol 80: 199-202.

Figadère B, Munoz-Durango K, Maciuk A, Londono J, Arrango Acosta GJ 2010. New method for detecting antimalarial drugs. PCT Int. Appl., 97pp. WO 2010103025 (A1) 2010-09-16.

Fivelman QL,Adagu IS, WarhurstDC2007.Effects of piperaquine, chloroquine, and amodiaquine on drug uptake and of these in combination with dihydroartemisinin against drug-sensitive and -resistant Plasmodium falciparum strains. Antimicrob Agents Chemother 51: 2265-2267.

Froelich S, Onegi B, Kakooko A, Siems K, Schubert C, JennetSiems K 2007. Plants tradicionally used agains malaria: phytopchemical and pharmacological investigation of Momordica foetida. Rev Bras Farmacogn 17: 1-7.

Garavito G, Monje MC, Maurel S, Valentin A, Nepveu F, Deharo E 2007. A non radiolabeled heme-GSH interaction test for the screening of antimalarial compounds. Exp Parasitol 116: 311-313.

Gray AI, Waigh RD, Waterman PG 1977. Cis-avicennol, a new pyranocoumarin from the root bark of Zanthoxylum elephantiasis. Phytochemistry 16: 1017-1018.

Jacobson M 1948. Herculin, a pungent insecticidal constituent of Southern prickly ash bark. J Am Chem Soc 70: 42344237.

Jang KH, Chang YH, Kim DD, Oh KB, Oh U, Shin J 2008. New polyunsaturated fatty acid amides isolated from the seeds of Zanthoxylum piperitum. Arch Pharm Res 31: 569572.

Karioti A, Skaltsa H, Kaiser M, Tasdemir D 2009. Trypanocidal, leishmanicidal and cytotoxic effects of anthecotulidetype linear sesquiterpene lactones from Anthemis auriculata. Phytomedicine 16: 783-787.

Kurosawa Y, Dorn A, Kitsuji-Shirane M, Shimada H, Satoh T, Matile H, Hofheinz W, Masciadri R, Kansy M, Ridley RG 2000. Hematin polymerization assay as a highthroughput screen for identification of new antimalarial pharmacophores. Antimicrob Agents Chemother 44: 2638-2644.

Lozano R, Chitwood DJ, Lusby WR, Thompson MJ, Svoboda JA, Patterson GW 1984. Comparative effects of growth inhibitors on sterol metabolism in the nematode Caenorhabditis elegans. Comp Biochem Physiol C Comp Pharmacol 79: 21-26.

Luize PS, Tiuman TS, Morello LG, Maza PK, Ueda-Nakamura T, Dias Filho BP, Cortez DAG, De Mello JCP, Nakamura
CV 2005. Effects of medicinal plant extracts on growth of Leishmania (L.) amazonensis and Trypanosoma cruzi. Braz J Pharm Sci 41: 85-94.

Milliken W 1997. Malaria and antimalarial plants in Roraima, Brazil. Trop Doct 27 Suppl 1: 20-25.

Mosmann T 1983. Rapid colorimetric assay for cellular growth and survival: application to proliferation and cytotoxicity assays. J Immunol Methods 65: 55-63.

Pashynska VA, Van den Heuvel H, Claeys M, Kosevich MV 2004. Characterization of noncovalent complexes of antimalarial agents of the artemisinin-type and FE(III)heme by electrospray mass spectrometry and collisional activation tandem mass spectrometry. J Am Soc Mass Spectrom 15: 1181-1190.

Robert A, Coppel Y, Meunier B 2002. NMR characterization of covalent adducts obtained by alkylation of heme with the antimalarial drug artemisinin. Inorganica Chim Acta 339: 488-496.

Rush MA, Baniecki ML, Mazitschek R, Cortese JF, Wiegand R, Clardy J, Wirth DF 2009. Colorimetric high-throughput screen for detection of heme crystallization inhibitors. Antimicrob Agents Chemother 53: 2564-2568.

Sharrock WW, Suwanarusk R, Lek-Uthai U, Edstein MD, Kosaisavee V, Travers T, Jaidee A, Sriprawat K, Price RN, Nosten F, Russell B 2008. Plasmodium vivax trophozoites insensitive to chloroquine. Malar J 7: 94.

Soriano-Agatón F, Lagoutte D, Poupon E, Roblot F, Fournet A, Gantier JC, Hocquemiller R 2005. Extraction, hemisynthesis, and synthesis of canthin-6-one analogues. Evaluation of their antifungal activities. $J$ Nat Prod 68 : 1581-1587.

Spelman K, Depoix D, McCray M, Mouray E, Grellier P 2010. The traditional medicine Spilanthes acmella, and the alkylamides spilanthol and undeca-2E-ene-8,10-diynoic acid isobutylamide, demonstrate in vitro and in vivo antimalarial activity. Phytother Res In press, PTR-10-0925.

Spelman K, Wetschler MH, Cech NB 2009. Comparison of alkylamide yield in ethanolic extracts prepared from fresh versus dry Echinacea purpurea utilizing HPLCESI-MS. J Pharm Biomed Anal 49: 1141-1149.

Spichiger R, Stutz de Ortega L 1987. Fagara. In Spichiger R, Stutz de Ortega L (eds.) Flora de Paraguay: Rutaceae. St. Louis: Ed Conservatoire et Jardin botaniques de la Ville de Gen'eve, p. 19-36.

Tabanez MF, Durigan G, Keuroghlian A, Barbosa AF, de Freitas CA, da Silva CEF, da Silva, DA, Eaton DP, Brisolla G, de Faria HH, Mattos IFdA, Lobo MT, Barbosa MR, Rossi M, de Souza MdG, Machado RB, Pfeifer RM, Ramos VS, Andrade WJ D, Contieri WA 2005. In Florestal I. Plano de Manejo da Estação Ecológica dos Caetetus. Ed São Paulo, p. 1-103.

Tekwani BL, Walker LA 2005. Targeting the hemozoin synthesis pathway for new antimalarial drug discovery: Technologies for in vitro $\beta$-hematin formation assay. Comb Chem High Throughput Screen 8: 63-79.

Thouvenel C, Gantier JC, Duret P, Fourneau C, Hocquemiller R, Ferreira ME, Rojas de Arias A, Fournet A 2003. Antifungal compounds from Zanthoxylum chiloperone var. angustifolium. Phytother Res 17: 678-680.

Weissbuch I, Leiserowitz L 2008. Interplay between malaria, crystalline hemozoin formation, and antimalarial drug 
The antiplasmodium effects of a traditional South American remedy: Zanthoxylum chiloperone var. angustifolium against chloroquine resistant and

action and design. Chem Rev 108: 4899-4914.

Xiong Q, Shi D, Yamamoto H, Mizuno M 1997. Alkylamides from pericarps of Zanthoxylum bungeanum. Phytochemistry 46: $1123-1126$.

Yang X 2008. Aroma constituents and alkylamides of red and green huajiao (Zanthoxylum bungeanum and Zanthoxylum schinifolium). J Agric Food Chem 56: 1689-1696.

\section{*Correspondence}

\section{Alain Fournet}

Laboratoire de Pharmacognosie associé au CNRS, UMR 8076

BioCIS, Faculté de Pharmacie, Université Paris-Sud

5, rue Jean-Baptiste Clément, 92296 Châtenay-Malabry CEDEX, France

alain.fournet@ird.fr

Tel.: +33 (0)146835969

Fax: +33(0)146835399 